\title{
Relationship between University Students' Social Responsibility (USSR) and Mental Health (Case Study, the University of Guilan, Faculty of Humanities, Iran)
}

Dr Abbas Sadeghi

Associate Professor, the University of Guilan, Iran

Dr Farhad Asghari

Assistant Professor, the University of Guilan, Iran

\author{
Mehdi, Yekrang Safakar
}

General Psychology Student

\author{
Atefeh Sadeghi \\ MA in English Language Teaching, the University of Guilan, Iran \\ E-mail: asadeghi_2003@yahoo.com
}

Doi:10.5901/mjss.2014.v5n7p504

\section{Abstract}

The main aim of the present study is the survey of relationship between (USSR) with mental health in the University of Guilan. The research statistic society included all students of faculty of humanities of University of Guilan in the 2010-2011 academic years, using of method cluster sampling on the basis of Kerjeci and Morgan and taxonomy sampling. 350 students were chosen and 350, teacher made questionnaires with $82 \%$ Chronbach Alpha in reliability and 3 Counseling and Psychology academic staffs' corrections for validity, were completed and returned. The research method was descriptive-analytical and data analysis used as percent, frequency and one way variance analysis (ANOVA). In conclusion, except hypothesis 5 (the efficacy of suitable competition on mental health) and second part of hypothesis 8 (help students in no scholastic affairs), the rest of hypothesises including the relationship between time management, constructive feedback, active listening, team activities, discussions, questioning and answering and help to students with mental health, HO hypothesises were rejected and hypothesis research were approved. Also, there were no significant differences with assurance $95 \%$ between students' gender, age, the year of entrance to the university and academic mark average. Therefore, most of students believed that the (USSR) improve their mental health.

Keywords: social responsibility, mental health, student

\section{Introduction}

Maintaining mental and physical health is counted as one of the most important tasks in the human life. Health and safety are two God gifts which while we loose them we will find their values. Iranian culture emphasis on the human beings who has physical and mental health so that they could meet own aims. Ahmadi (1989) pointed out that Islam tries to consider prevention before treatment. It means, the main aim of Islamic thought maintaining mental and physical health in minimum cost. One of the most important issues in mental health is USSR, in particular, in young students. Unfortunately, with respect to authors' experiences the mental health of students is not so high due to shortage of USSR. The reasons may alert to academic staffs, managers or policy makers in higher education, but it can not be ignored the role of family, school and even public culture. The key issue in the paper is attracts academic staff members views to the factors affecting on USSR in practice in mental health process. They must focus on responsibility in their class management in order to create responsibility culture. We hope the paper conclusions can help necessary changes in mental health towards USSR. 


\section{Necessity and Importance of Mental Health}

According to Ganji (1998) WHO believes that thought health means the capability is rhythmic, harmonious relationship with others, individual and social changing and modifying also solving personal conflicts and tendencies in a logical and proper manner. Mir Kamali (1998) believed that mental health is the prevention of mental illness and creating safe mental environment so that people can communicate with others in a balance personality and try to actualize their attitudes and meet their individual and social aims and needs. With respect to the above mentioned definitions it can be concluded that the main aim of the mental health is the prevention and treatment of mental disorders for a successful social environment and self and safe adaptation. Khosravi (2000) believes that in a unbalanced and fast world with high tiredness which mental problems like poverty, war and corruption are increased, the only way to save human being is pay more attention to positive thinking and internal development. According to Shafee Abadi (1996) the human being does not experience tension and does not feel pain when his mental needs have met and show its moral behaviors. Human being with regard to special points in one hand can guarantee his mental health before treatment and other hand can prevent maladjustment or bad adjustment behavior.

\section{Social Responsibility and Mental Health}

According to Rahimian (2000) psychoanalysts believe, the personal health is developed. While "ego" promotes in personality structure and can solve "id" and "super ego" "conflicts" in basis of wisdom and logic. Other psychologists emphasized that every body that are safe and sound in structure of personality he can develop his social development and can create good relationship with others. He also believes that today psychologists emphasize on the mutual relations health body and soul. In the sense that having a mental health requires physical health and having a physical health requires mental health.

\section{Research Methodology}

The research method in the present study is descriptive-analytical type and research statistic society were all students of faculty of humanities of Guilan University in the 2010-2011 academic years, that was using the table kerjcie and Morgan (1970).

\section{The Method Sampling}

350 students were chosen as a statistical sample and all questionnaires completed and returned. The research instrument was questionnaire in Likert Scale (full no agreement, no agreement, no idea, full agreement, agreement) with 49 questions. Also, validity and reliability have been measured through pilot study. For reliability, the Chronbach Alpha was $85 \%$ and for validity the viewpoints of 3 Counseling and Psychology academic staffs' corrections, have been done.

\section{Research Hypothesis and Question}

\subsection{Main Hypothesis}

There is relationship between USSR and mental health and subdivision Hypothesis are:

Hypothesis 1: There is relationship between time management and mental health

Hypothesis 2: There is relationship between constructive feedback and mental health

Hypothesis 3: There is relationship between active listening and mental health

Hypothesis 4: There is relationship between team activities and mental health

Hypothesis 5: There is relationship between proper competition and mental health

Hypothesis 6: There is relationship between class discussion and mental health

Hypothesis 7: There is relationship between question and answer process and mental health

Hypothesis 8: There is relationship between helping students inside and outside the class and mental health

\subsection{Research Question}

Are there any differences among students with respect to gender, age, entering year, and mark average? 


\section{Research Findings}

Research findings presented in two different sections:

\subsection{Data description}

This study which have been done one basis of data among 350 humanities students in Guilan university consisted of 210 female (60 percent) and 140 male (40 percent). The age scope statistics were between $20-30$ years old with $80 \%$ for under $25-20$ years old and 20\% 25-30 up years old.

\subsection{The amount of mental health}

The following table shows the distribution of students' mental health which have been measured by a two options question:

Table 1: mental health responds frequency distribution

\begin{tabular}{|c|c|c|c|}
\hline & $F$ & $P$ & CP \\
\hline Yes & 203 & 58 & 68 \\
\hline No & 147 & 42 & 100 \\
\hline Total & 350 & 100 & \\
\hline
\end{tabular}

The above mentioned table shows that $58 \%$ of students had high and $42 \%$ low mental health.

\section{Hypothesis and research question Analysis}

Table 2: Hypothesis 1

There is relationship between time management and mental health

$\begin{array}{lllll}\text { full no agreement } & \text { no agreement } & \text { no idea } & \text { agreement } & \text { full agreement } \\ 3 \% & 10 \% & 10 \% & 39 \% & 38 \%\end{array}$

Based on the results of above table, $77 \%$ of the students believed that there is relationship between time management and mental health, $13 \%$ did not confirm such relationship and $10 \%$ were uncertain.

Table 3: Hypothesis 2

There is relationship between constructive feedback and mental health

\begin{tabular}{|c|c|c|}
\hline $\begin{array}{l}\text { full no agreement } \\
12 \%\end{array}$ & $\begin{array}{l}\text { no agreement } \\
8 \%\end{array}$ & $\begin{array}{l}\text { no idea } \\
7 \%\end{array}$ \\
\hline
\end{tabular}

Based on the results of table 3,73\% of the students believed that there is relationship between constructive feedback and mental health, $20 \%$ did not confirm such relationship and $7 \%$ were uncertain.

Table 4: Hypothesis 3

There is relationship between active listening and mental health

$\begin{array}{lllll}\text { full no agreement } & \text { no agreement } & \text { no idea } & \text { agreement } & \text { full agreement } \\ 15 \% & 20 \% & 4 \% & 28 \% & 33 \%\end{array}$

Based on the results of above table $61 \%$ of the students believed that there is relationship between active listening and mental health, $35 \%$ did not confirm such relationship and $4 \%$ were uncertain. 
Table 5: Hypothesis 4

There is relationship between team activities and mental health

$\begin{array}{lclll}\text { full no agreement } & \text { no agreement } & \text { no idea } & \text { agreement } & \text { full agreement } \\ 10 \% & 20 \% & 4 \% & 28 \% & 38 \%\end{array}$

Based on the results of above table $66 \%$ of the students believed that there is relationship between team activities and mental health, $30 \%$ did not confirm such relationship and $4 \%$ were uncertain.

Table 6: Hypothesis 5

There is relationship between proper competition and mental health

$\begin{array}{lllll}\text { full no agreement } & \text { no agreement } & \text { no idea } & \text { agreement } & \text { full agreement } \\ 19 \% & 45 \% & 8 \% & 10 \% & 18 \%\end{array}$

Based on the results of above table $64 \%$ of the students believed that there is not relationship between proper competition and mental health, $28 \%$ confirm such relationship and $8 \%$ were uncertain.

Table 7: Hypothesis 6

There is relationship between discussion and mental health

$\begin{array}{lllll}\text { full no agreement } & \text { no agreement } & \text { no idea } & \text { agreement } & \text { full agreement } \\ 20 \% & 8 \% & 7 \% & 12 \% & 53 \%\end{array}$

Based on the results of above table $65 \%$ of the students believed that there is relationship between discussion and mental health, $28 \%$ did not confirm such relationship and $7 \%$ were uncertain.

Table 8: Hypothesis 7

There is relationship between question and answer and mental health

$\begin{array}{lllll}\text { full no agreement } & \text { no agreement } & \text { no idea } & \text { agreement } & \text { full agreement } \\ 15 \% & 20 \% & 4 \% & 28 \% & 33 \%\end{array}$

Based on the results of above table $61 \%$ of the students believed that there is relationship between question and answer and mental health, 35\% did not confirm such relationship and $4 \%$ were uncertain.

Table 9: Hypothesis 8

There is relationship between helping students and mental health (inside class)

$\begin{array}{lllll}\text { full no agreement } & \text { no agreement } & \text { no idea } & \text { agreement } & \text { full agreement } \\ 15 \% & 10 \% & 10 \% & 30 \% & 35 \%\end{array}$

Based on the results of above table $65 \%$ of the students believed that there is relationship between helping students and mental health inside the class, 25\% confirm such relationship and 10\% were uncertain.

There is relationship between helping students and mental health (outside class)

$\begin{array}{lllll}\text { full no agreement } & \text { no agreement } & \text { no idea } & \text { agreement } & \text { full agreement } \\ 45 \% & 22 \% & 3 \% & 12 \% & 18 \%\end{array}$

Based on the results of above table $67 \%$ of the students believed that there is no relationship between helping students and mental health outside the class, $30 \%$ did not confirm such relationship and $3 \%$ were uncertain. 
Table 10: Split on Gender

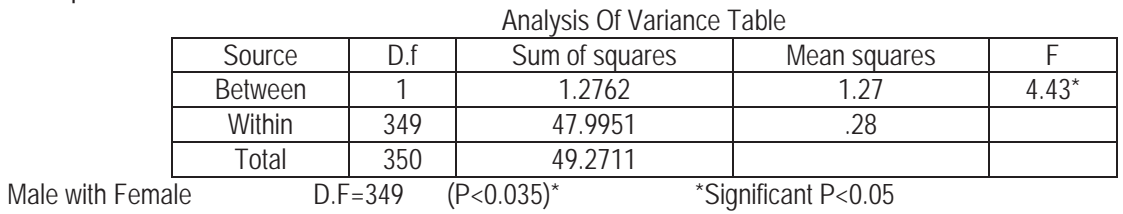

Table 11: Split on age

\begin{tabular}{|c|c|c|c|c|}
\hline \multicolumn{5}{|c|}{ Analysis Of Variance Table } \\
\hline Source & D.f & Sum of squares & Mean squares & $\mathrm{F}$ \\
\hline Between & 1 & 1.2616 & 1.26 & $4.50^{*}$ \\
\hline Within & 349 & 48.0096 & .28 & \\
\hline Total & 350 & 49.534 & & \\
\hline
\end{tabular}

Table 12: Split on entering year

Analysis Of Variance Table

\begin{tabular}{|c|c|c|c|c|}
\hline Source & D.f & Sum of squares & Mean squares & $\mathrm{F}$ \\
\hline Between & 1 & 1.6581 & 1.65 & $6.34^{*}$ \\
\hline Within & 349 & 45.9803 & .26 & \\
\hline Total & 350 & 47.6385 & & \\
\hline
\end{tabular}

Before 2006-after 2006

D.F=349 $(P<0.013)^{\star} \quad{ }^{*}$ Significant $P<0.05$

Table 13: Split on average mark

\begin{tabular}{|c|c|c|c|c|}
\hline \multicolumn{5}{|c|}{ Analysis Of Variance Table } \\
\hline Source & D.f & Sum of squares & Mean squares & $\mathrm{F}$ \\
\hline Between & 1 & 1.3332 & 1.75 & $6.25^{\circ}$ \\
\hline Within & 349 & 45.3200 & .28 & \\
\hline Total & 350 & 47.7676 & & \\
\hline
\end{tabular}

Therefore, with regard to table 2, there are no differences between responsibility and mental health with respect to gender, age, entering year and mark average.

\section{Conclusion and Discussion}

The present research have studied the relationship between USSR such as time management, constructive feedback , active listening, proper competition in class discussion, question and answer inside classes and help students inside and outside class.

The hypotheses analysis show that except hypotheses number 5 (relationship between proper competition and mental health) and the second section of 8 theory (relationship between helping students and mental health (outside class)

The rest of hypotheses have been confirmed. It seems, in respondents' viewpoints, the weight of competition was so heavy and we should explain more about it. Also, students had not enough time to help each other In general; the conclusions show the USSR factors have close relationship with mental health.

Also in the second part of the research show that there are no differences between USSR and mental health with respect to gender, age, entrance year and mark average. The conclusions have been compared with other research finding or academic viewpoints separately:

Hypothesis 1: There is relationship between time management and mental health.

This conclusion has been confirmed by Frazer and Hay ton (2009) Mackie (2010) Baron (2008), Stephen and et.al (1992) research findings.

Hypothesis 2: There is relationship between constructive feedback and mental health.

This conclusion has been confirmed by (2008) Khosravi (2000) and Imgvist (2009) research findings.

Hypothesis 3: There is relationship between active listening and mental health. 
This conclusion has been confirmed by Mir Kamali (1998), Khosravi (2000) Frazer and Hay ton (2009) and Herman and et.al (2008) research findings.

Hypothesis 4: There is relationship between team activities and mental health.

This conclusion has been confirmed by Mir Kamali (1998) and et.al, Hermann (2008) Mackie (2010) Imgvist and (2009) research findings.

Hypothesis 5: There is no relationship between proper competition and mental health.

This conclusion has been confirmed by Khosravi (1999) Mackie (2010) and Baron (2008) research findings.

Hypothesis 6: There is relationship between discussion and mental health.

This conclusion has been confirmed by Mir Kamali (1998), Frazer and Hay ton (2009) research findings.

Hypothesis 7: There is relationship between question and answer and mental health.

This conclusion has been confirmed by Mir Kamali (1998), Hermann (2008), Imgvist (2009) research findings.

Hypothesis 8: There is relationship between helping students and mental health (inside class) and there is no relationship between helping students and mental health (outside class).

This conclusion has been confirmed by Mir Kamalhi (1998), Hermann (2008) Mackie (2010), Imgvist (2009) and Baron (2008) research findings.

Research Question: Are there any differences among students with respect to gender, age, year entrance, and mark average relationship between helping students and mental health

This conclusion has been confirmed by Mir Kamal (1998), Fraser and Hay ton (2009) research findings.

\section{Suggestions}

\section{- To Academic Staff Members}

1. Focus on the time management importance.

2. Have positive, proper and constructive feed back on behavioral and study affairs to their students.

3. Provide opportunities for team working in their students.

- To students

1. Do life responsibilities through doing their study responsibilities.

2. Should not be passive inside classes.

3. Consider time management in all steps of their life.

- To University

1. Consider a lesson by the name of responsibility skill during their period of study.

2. Consider a lesson by the name of mental health for all students not just for Psychology and Counseling discipline.

3. Consider some more roles in research and academic affairs for students.

\section{References}

Ahmadi, Ali Asghar (1988) Mental Illness and Health, Education Monthly Journal. Tehran, Iran

Baron David (2008) Managing contracting and corporate social responsibly. Journal of Public Economics. Volume 92- Issue 1-2. pp 268288.

Fraser, a Gatherer. Hay ton, P (2009) Mental Health in Prisons: GreatDifficulties but are there opportunities. Public Health. Volume 123. Issue 6. Pp410-414.

Ganji, Hamzeh (1977) Mental Health. Arasbaran Publications. Tehran. Iran.

Herman, H. Moodie, R. Saxena (2008) mental health promotion. International Encyclopedia Health. Pp. 406-418.

Imgvist Michael Ho (2009) corporate social responsibility as corporate social Control: the case of Worke-site health promotion. Scandinavia Journal of Management, Volume 25. pp 68-72.

Kerjcie R V. Morgan (1970) Determining Sample size for Research Activities. Educational and Psychological Measurement. No 30. pp136p156.

Khosravi, Zohreh (1999) Is Religions the Factor for mental disorder or Health. Education Monthly Journal. Tehran, Iran

Mackie, P (2010) Social justice and social (responsibility) to wards a value base for global public health. Public Health, Volume 124, Issue 11. pp 620-625.

Mir Kamali, Sayyed Mohammad (1998) Mental Health in the School. Management in School Journal. Tehran. Iran.

Rahimian, Hoorieh, Banoo (1999) Mental Health. Payvand Monthly. The Ministry of Education. Tehran. Iran

Stephen R. Rosenthal, Mohan V. Tatikonda (1992) Time management in new product development: case study findings. Journal of Manufacturing systems. Volume 11. Issue 5. pp 359-368.

Shafi Abadi, Abdullah (1995) Counseling and Guidance. Alameh Tabatabee University Publication. Tehran. Iran. 